Conclusion Safety checklists were a popular intervention and had good uptake when launched on our unit. They have improved staff confidence during intubations, supporting safer care, good documentation, and education and training.

\section{G111(P) HAVE WE HIT THE MARK? BOOSTING CONFIDENCE TO IMPROVE OUTCOMES IN STRESSFUL SITUATIONS}

${ }^{1} \mathrm{~L}$ Rehman, ${ }^{2} \mathrm{M}$ Kamal, ${ }^{1} \mathrm{P}$ Cahill, ${ }^{3} \mathrm{M}$ Hussain, ${ }^{1} \mathrm{M}$ Shahid. 'Paediatrics Department, Portiuncula University Hospital, Ballinasloe, Ireland; ${ }^{2}$ Paediatric Emergency Department, Tallaght University Hospital, Dublin, Ireland; ${ }^{3}$ Department of Children and Young People, North Cumbria Integrated Care, Cockermouth, UK

\subsection{6/archdischild-2020-rcpch.88}

Aim

- To analyse whether initial consultant-led simulation-basedteaching-sessions (SBTS) boost junior doctors participation levels' as team leaders.

- To determine the influence of SBTS on non-clinical hospital doctors (NCHDs) baseline knowledge, confidence, comfort levels and situational awareness in stressful Paediatric/ Neonatal situations.

Method A two-part survey was designed and distributed at the start of the rotation in a formal setting of 'SAFE' (Situational Awareness For Everyone) by lead consultant. ${ }^{1}$ The first part included a comprehensive questionnaire outlining Paediatric BLS, ALS and Neonatal resuscitation to assess the baseline knowledge of all NCHDs. The second part helped us establish NCHDs experience, confidence and comfort levels when participating in SBTS sessions. ${ }^{1} 2$ Initial three months: Neonatal and Paediatric team leaders were designated among consultants to plan/coordinate among all NCHDs. A schedule of weekly Paediatric/Neonatal scenarios was distributed. Second three months: Team members volunteered to lead random scenarios per week. Overtime, situational awareness of team members was also assessed. ${ }^{1}$ After six months, the same survey was redistributed.

Results NCHDS' were categorised according to their level of experience in Paediatrics. NCHDs' who had between 0-1 years' experience in Paediatrics were not very confident and not very comfortable as team leaders and scored on average $63 \%$ on the baseline knowledge questionnaire. Post intervention most NCHDs had become very confident and very comfortable dealing with stressful situations and better retained baseline knowledge, scoring an average of 92\%. NCHD's who had $3+$ years' experience were confident and comfortable to begin with and those levels only improved over six months. ${ }^{1}$ 2 Baseline knowledge was maintained, further refining from $81-96 \%$.

Conclusion Our main cohort of junior doctors is GP trainees who rotate from different specialities every six months with none - minimal Paediatric/Neonatal exposure and knowledge as evident from the above results. Initially they were reluctant to participate due to the fear of being judged. However, our consultant-led strategy boosted their knowledge, confidence and comfort levels as well as situational awareness to lead and deliver better patient care in stressful situations.

\section{REFERENCES}

1. Rakshasbhuvankar, Abhijeet \& Patole, Sanjay. (2014). Benefits of simulation based training for neonatal resuscitation education: A systematic review. Resuscitation. 85. 10.1016/i.resuscitation.2014.07.005.
2. Schweich PJ, DeAngelis C, Duggan AK. Preparedness of practicing pediatricians to manage emergencies. Pediatrics 1991;88:223.

\section{G112(P) ARE WE FACING THE FUTURE? A REVIEW OF ACUTE GENERAL PAEDIATRIC ADMISSIONS AT A REGIONAL PAEDIATRIC HOSPITAL}

T Kendrew-Jones, S Farquharson, E Stewart, O Forbes, R Bland, L Nairn. General Paediatrics, Royal Hospital for Children, Glasgow, UK

\subsection{6/archdischild-2020-rcpch.89}

Aims To assess whether the Royal College of Paediatrics and Child Health 'Facing the Future: Standards for acute general paediatric services' (2015) are being achieved and if changes to service have improved performance.

Method Between May and August 2018 there was a phased reconfiguration of services, with merging of two inpatient units and redesign of middle grade and consultant rotas at our tertiary paediatric hospital $(68,000$ unscheduled care attendances per annum). This redesign has ensured compliance with Standards 1,4 and 6-10. We performed a retrospective case note review of admissions in May and September 2018 to assess performance against Standards 2, 3 and 5. A list of all acute general paediatric admissions was obtained and electronic patient records for every patient admitted on 12 preselected days each month were reviewed to document when children were first reviewed by senior clinicians (tier 2 doctors and consultants).

Results 219/265(82.6\%) patients were reviewed by a tier 2 doctor or above in May 2018 and 244/284(85.9\%) in September 2018 (table 1). Review within 4 hours occurred in $124 / 265(46.8 \%)$ in May and 159/284(56\%) in September. Most patients admitted over 14 hours had a consultant review during admission (87.9\% in May and $79.3 \%$ in September); however, this review was often out with 14 hours.

\begin{tabular}{|c|c|c|c|}
\hline & RCPCH & May-18 & Sept-18 \\
\hline & Standard & & \\
\hline General paediatric admissions ( $\mathrm{n}$ ) & & 784 & 744 \\
\hline Cases reviewed (n) & & 265 & 284 \\
\hline Tier 2 or above review during admission $(n ; \%)$ & & $219(82.6 \%)$ & $244(85.9 \%)$ \\
\hline Tier 2 or above review $\leq 4$ hrs $(n ; \%)$ & 2 & $124(46.8 \%)$ & $159(56 \%)$ \\
\hline $\begin{array}{l}\text { Seen or discussed with Tier } 2 \text { or above before } \\
\text { discharge }(n ; \%)\end{array}$ & 5 & $232(87.5 \%)$ & $258(90.8 \%)$ \\
\hline Patients admitted $>14$ hrs (n) & & 116 & 116 \\
\hline Consultant review during admission $(n ; \%)$ & & $102(87.9 \%)$ & $92(79.3 \%)$ \\
\hline Consultant review $\leq 14$ hrs $(n ; \%)$ & 3 & $33(28.4 \%)$ & $35(30.2 \%)$ \\
\hline
\end{tabular}

Conclusion Facing the Future Standards were considered during the design of acute paediatric services. We achieve seven of ten standards, with senior clinician review of most children during admission. However, with a large volume of unscheduled care attendances, early review remains the biggest challenge. Subsequent changes to our service have included expansion of consultant workforce and relocation of senior clinicians to the Emergency Department. 2019 data are collected and being analysed for comparison. 